\title{
THE EFFECT OF TOPICAL APPLICATION OF APPLE VINEGAR ON STRIAE GRAVIDARUM: A RANDOMIZED CLINICAL TRIAL
}

\author{
MARYAM ESHGHIZADEH ${ }^{1}$, MAHDI BASIRIMOGHADDAM ${ }^{1}$, SAMANE NAJAFI ${ }^{2 *}$, ZAHRA REZVANIFAR $^{3}$, \\ MAHDIEH ATARODI ${ }^{3}$, MAHBOOBEH BAGHBAN ${ }^{3}$
}

\begin{abstract}
${ }^{1}$ Department of Medical-Surgical Nursing, Faculty of Nursing, Gonabad University of Medical Sciences, Gonabad, Iran. ${ }^{2}$ Department of Medical-Surgical Nursing, Faculty of Nursing, Department of Family Health, Social Development \& Health Promotion Research Center, Gonabad University of Medical Sciences, Gonabad, Iran. ${ }^{3}$ Student Research Committee, Gonabad University of Medical Sciences, Gonabad
\end{abstract} Iran. Email: S.Najafi2012@yahoo.com

Received: 03 March 2018, Revised and Accepted: 11 April 2018

ABSTRACT

Objective: Striae happen to 50-90\% of pregnant women and never disappears completely. It is, therefore, a major aesthetic concern for most women, which can cause psychological distress and disturbed body image. This study was conducted to examine the effectiveness of the topical use of apple vinegar on striae gravidarum.

Methods: This randomized controlled clinical trial study was conducted on 23 women referred to health centers in Gonabad city, selected according to inclusion criteria and systematic random method. The right half of the abdomen in each participant was considered as a trial group and the left half as the control. On the trial side, apple vinegar was massaged onto striae twice daily for 1 month. Data were collected using a demographic questionnaire, checklist of striae aesthetic change, a pair of calipers and a camera and analyzed in SPSS-20 using descriptive statistics, paired t, and Wilcoxon tests at significance level $\mathrm{p}<0.05$.

Results: No significant change was observed in mean length and width of striae in either trial or control sides after the intervention ( $p>0.05$ ). However, on the trial side, the difference between striae length and width before and after the intervention was statistically significant ( $\mathrm{p}<0.001$ ). A significant difference was observed during intervention in the reduction in striae length and width on trial side $(\mathrm{p}<0.001)$.

Conclusion: Topical application of apple vinegar effectively reduces the size of striae. Further and longer studies with larger sample size are recommended.

Keywords: Striae gravidarum, Apple vinegar, Women, Body image.

(C) 2018 The Authors. Published by Innovare Academic Sciences Pvt Ltd. This is an open access article under the CC BY license (http://creativecommons. org/licenses/by/4. 0/) DOI: http://dx.doi.org/10.22159/ajpcr.2018.v11i7.25592

\section{INTRODUCTION}

Skin is a determining factor in human beauty, and its health and vitality are indicative of general and psychological health. During pregnancy, skin experiences certain physiological changes that may concern pregnant women; one of these changes is striae, which are line-like lesions that commonly appear as reddish purple lines after the $24^{\text {th }}$ week of pregnancy [1]. After pregnancy, these lesions gradually fade away, and skin atrophy occurs, but they never disappear completely [2,3]. These marks often occur on the abdomen, thighs, buttocks, and breasts even after the first pregnancy [3]. Prevalence of striae has been reported $50-90 \%$, which is relatively high [4].

Many risk factors have been proposed for striae, including mother's baseline weight, weight gain during pregnancy, maternal age, neonatal birth weight, maternal race, skin type, gestational diabetes, poor nutrition, family history, and childbirth method [5]. However, the role of many of these is yet to be confirmed [4,6,7]. It is believed that these lesions are mainly caused by mechanical stretching of the skin associated with hormonal factors. Striae are caused by changes in connective tissue, which include reduced elastin and fibrin in the skin [8].

Due to physiological and hormonal changes on the one hand, and aesthetic changes on the other, pregnancy can disturb body image and thus reduce self-esteem in women. Striae gravidarum are an important factor affecting women's body image [9], and displeasure with the mental image during and after pregnancy may, directly and indirectly, affect maternal and fetal health [10]. Studies have shown that some of the psychological problems during pregnancy and postpartum are associated with marks left from striae in various parts of the body [11]. Since these changes are considered physiological; they are less attended to by doctors. Yet, it seems striae are very unpleasant for many women, especially in the abdomen area, which forces women to resort to various painful, expensive, and mostly ineffective treatment methods [12,13]. Treatments available for improving the appearance of striae include laser, erosive skin laser, topical retinoids, and skin shaving. Laser treatment has the most complications, which, especially affect darker skinned patients [14]. It has been suggested that time is the only treatment of striae, and that mark will fade away and return to normal in time, which is not the right solution. Many primipara women or those planning for pregnancy seek to learn about factor causing striae and ways to prevent them [15]. Traditionally, one way to prevent striae is through the application of topical lubricants, with some reports of success [16]. The main mechanism of action of these lubricants is through skin hydration. Sweet almond, wheat bran, and olive oils possess such properties [17]. Clearly, creams and lotions can reduce dryness of the skin and can be used as a cure for skin rash accompanying striae [18]. Previous studies have rejected effectiveness of olive oil [3], bitter almond oil [19], and cocoa cream [20] for prevention or treatment of striae, but proposed teak wood cream [3] and sweet almond oil $[21,22]$ effective in reducing the severity of striae. Herbal-therapies (such as the use of essential oils and cocoa cream) are among applications of complementary medicine for treatment or prevention of striae, which are preferred over invasive methods such as laser-therapy and cosmetic surgery due to their negligible side-effects and low costs. 
Traditional medicine also recommends the application of natural apple vinegar onto striae. Some scientists refer to apple vinegar as an elixir of health. The book of Al-Hawi asserts that apple vinegar is effective in cleansing the wound and preventing its swelling. Many traditional medicine books have cited properties of apple vinegar in the treatment of dandruff and itching, eliminating facial brown spots, reducing facial acne and freckles, and skin rash [23]. Apple vinegar is also highly useful in the treatment of warts, corns, skin moles, and skin irritations. With its acidic properties, apple vinegar maintains skin health and vitality [24].

Considering apple vinegar's useful compounds, availability, low costs, and simplicity of use, and lack of studies similar to what is intended in the present study; this study was conducted to determine the effect of topical application of apple vinegar on striae gravidarum. The aim of this study was to investigate the effects of a topical application of apple vinegar on striae gravidarum.

\section{METHODS}

\section{Study design}

This is a controlled randomized clinical trial study.

\section{Setting and samples}

The study population consisted of all women with striae gravidarum attending urban, public, and outpatient health centers in Gonabad city. Samples included 23 women with striae gravidarum attending 3 health centers in 2014 that were selected according to study inclusion criteria and systematic random sampling method. Following a pilot study, and using the following equation, the sample size in each group was found 20 women, which was increased to 25 taking into account possible withdrawals. Ultimately, two women were excluded for declining to take part. Study inclusion criteria were: (1) Having striae gravidarum; (2) aged between 20 years and 30 years; (3) one or two parties; (4) no twin or multiple pregnancy; (5) postpartum, no more than 9 months; (6) no history of preterm childbirth; (7) $18.5<$ body mass index $(\mathrm{BMI})<25$; and (8) no abdominal open wound or hematoma. Study exclusion criteria were: (1) Lack of follow-up and withdrawal request at any stage; (2) any skin allergy or reaction; and (3) use of any other cream or medication.

\section{Measurements and instruments}

The data collection tool comprised: (1) Personal details and demographic questionnaire; (2) checklist of aesthetic changes of striae; (3) calipers (for precise measurement of striae length and width); (4) camera; and (5) treatment efficacy assessment questionnaire according to participants. The personal details questionnaire included age, weight, height, BMI, gravidity, weight gain in pregnancy, birth interval, skin type, birth weight, mother's occupation and education, spouse's occupation and education, and place of residence. The checklist of striae appearance change included striae length, width, and color. Participants' treatment efficacy assessment questionnaire was based on 4-point Likert scale, including good, average, low, and no comment options. The validity of these questionnaires and the checklist was assessed using the content validity method. To this end, views were sought about questionnaires from 10 experts in gynecology and obstetrics, midwifery and nursing, and those familiar with questionnaire design. Reliability of the calipers and the camera was assessed using equivalent reliability methods.

\section{Data collection and procedure}

A letter of introduction was obtained from the Research Deputy of Gonabad University of Medical Sciences, and health centers were visited, and participants were selected according to systematic random sampling method. First, study objectives were explained and informed written consents were obtained from participants. Before the intervention, the personal details questionnaire was completed through self-report and interview, and checklist of striae aesthetic changes was completed using calipers. Using a camera, pictures were taken and coded from striae on both sides of the abdomen. To control confounding factors in each sample, the right side of the abdomen was taken at the trial side, and the left as controls. The proper intervention method was taught to mothers by a nurse in the first session. For intervention on the trial side, the first abdomen was cleansed on both sides using cotton soaked in pure water (no soap). Then, cotton soaked in apple vinegar was dabbed onto the right side twice daily for 1 month. Once vinegar, dried in air (taking about $15 \mathrm{~min}$ ), the right side was cleansed with cotton soaked in pure water. The apple vinegar was composed of one teaspoon of apple vinegar (Zamani, Iran) with $4 \%$ acidity in one teaspoon of pure water. At the end of each week of intervention, mothers visited the health center, and striae changes (length, width, and color) were measured using calipers, camera, and a checklist of aesthetic changes on both sides, and measurements were recorded. In the course of the intervention, participants were followed-up on a daily basis by phoning them to ensure the absence of side-effects and proper application of intervention. The participants' treatment efficacy assessment questionnaire was completed at the end of each week. By the end of the intervention, checklist of aesthetic changes (measured by calipers) was completed, and pictures were taken from striae on both sides (Fig. 1).

\section{Ethical considerations}

These included: (1) approval of the Regional Research Ethics Committee of Gonabad University of Medical Sciences (Code: GMU. REC.1392.50); (2) necessary arrangements with study setting; (3) participants' informed consents; (4) assuring participants about confidentiality of personal data, photos, and results; (5) withdraw at any stage; (6) coded photography of abdomen area only; and (7) registration of study at the Iran's Clinical Trials Registration Center (Code: IRCT2014040717160N1R1).

\section{Data analysis}

Data collected were analyzed in SPSS-20 software using descriptive (mean, standard deviation, relative frequency, and percentage) and inferential statistics (paired $t$-test and Wilcoxon rank-sign tests) at significant level $\mathrm{p}<0.05$.

\section{RESULTS}

The majority of participants had university degrees (47.8\%), followed by high school diploma (30.4\%). Most participants were housewives $(82.6 \%)$, and the rest were self-employed (4.3\%) or in the public sector (13.1\%), and $60.9 \%$ of husbands were self-employed, and the rest were employees (39.1\%). Of participants, 56.6\% rated the effect of treatment good. Other demographic details are shown in Table 1.

Table 2 presents paired $t$-test results comparing the mean length and width of striae on both sides before and after the intervention. No significant difference was observed in mean striae length and width between trial and control sides after intervention ( $p \geq 0.05)$, but this difference was statistically significant on the trial side before compared to after the intervention $(\mathrm{p}<0.001)$. The results obtained showed no significant difference in striae color before and after intervention on both trial and control sides. Wilcoxon rank-sign test showed a significant difference in reduced striae length and width on both trial and control sides $(\mathrm{p}<0.001)$.

\section{DISCUSSION}

This study aimed to assess the effect of topical application of apple vinegar on striae gravidarum. The results obtained showed no significant difference between two groups in terms of striae length and width before and after the intervention. However, there was a significant difference in striae length and width before and after the intervention on the trial side. Hence, although apple vinegar does not produce tangible aesthetic changes (like change in color), it can be said to be effective in reducing the length and width of striae. In this study, using the Graston technique on striae, Gandhi found no change in striae length in the course of treatment, but the skin had softened [25], which disagrees with the present study results; perhaps because the Gandhi's study was conducted on one patient over six sessions, and this study was performed on a larger sample size over 1 month (twice daily). Dung et al. used platelet-enriched plasma on striae over three sessions 


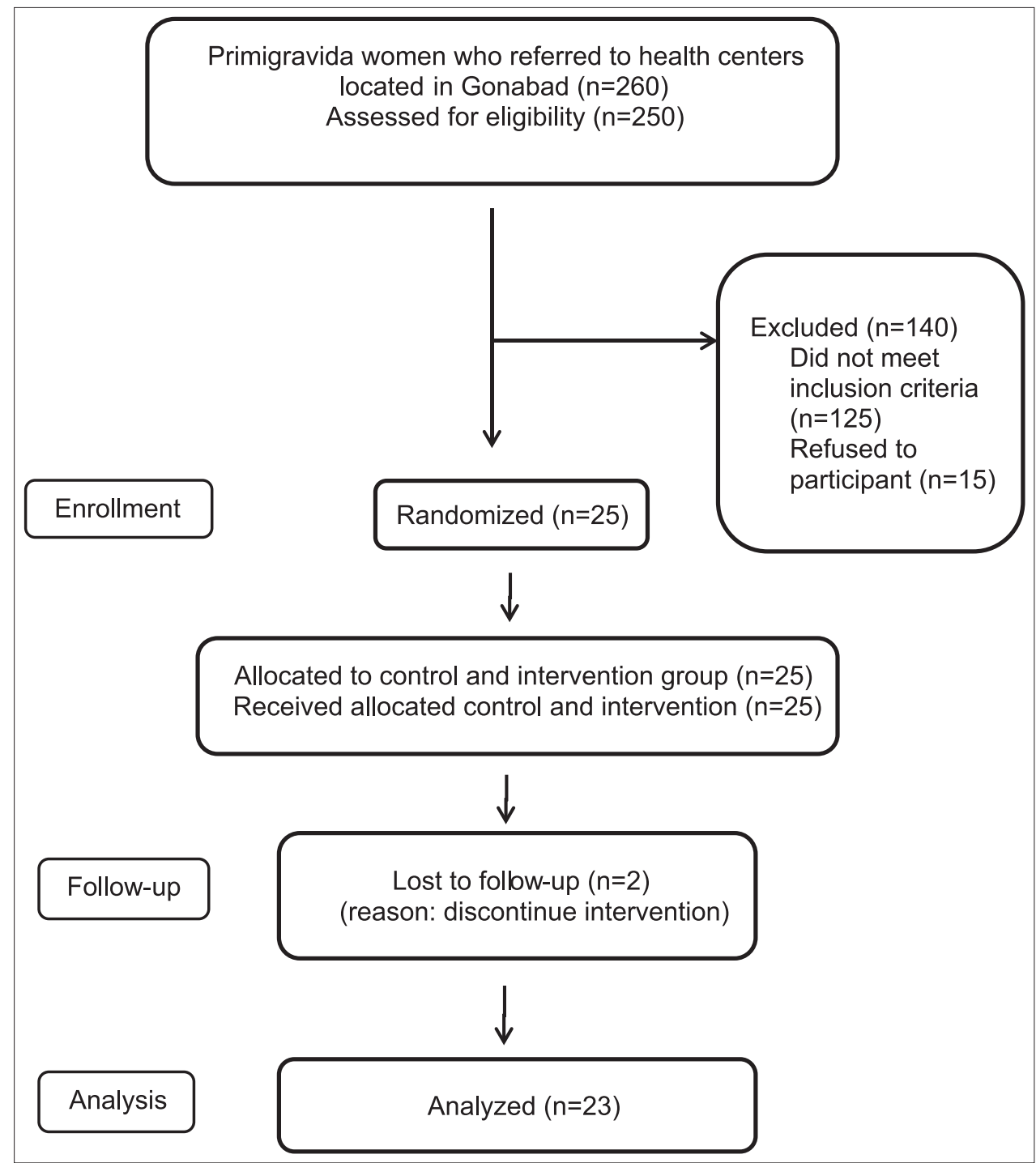

Fig. 1: CONSORT diagram of the study

Table 1: Demographic characteristics in both groups $(n=23)$

\begin{tabular}{ll}
\hline Demographic characteristics & Frequency \\
\hline Age, mean (SD), y & $26.13(4.84)$ \\
Weight, mean (SD), kg & $61.80(9.39)$ \\
Length, mean (SD), cm & $157.89(7.23)$ \\
BMI, mean (SD), kg/cm ${ }^{2}$ & $24.70(2.80)$ \\
Weight gain in pregnancy, mean (SD), kg & $13.67(4.90)$ \\
Birth interval, mean (SD), y & $3.52(1.67)$ \\
Birth weight, mean (SD), kg & $3.23(0.84)$ \\
Gravidity, n (\%)* & \\
First & $17(73.90)$ \\
Second & $6(26.10)$ \\
Skin type, n (\%)* & \\
Normal & $2(8.70)$ \\
Oily & $11(47.80)$ \\
Dry & $10(43.50)$ \\
\hline *Data available for 23 participants. SD: Standard deviation, BMI: Body mass \\
index
\end{tabular}

in 3 weeks. After 2 months, the results showed a mean reduction in the largest width from $0.75 \mathrm{~mm}$ to $0.25 \mathrm{~mm}$ [26], both groups were not significantly different. These results agree with those found in the present study.

The results of a study by Taavoni et al. conducted on 11 primiparous women in their second half trimester of pregnancy were not in favor of olive oil for preventing striae gravidarum [3]. In a study by Tashan and Kafkasli conducted on 141 primiparous women divided into three groups receiving bitter almond oil, $15 \mathrm{~min}$ abdominal massage with bitter almond oil, and 15 min abdominal massage alone, results showed that bitter almond oil alone was not effective in preventing striae compared to control group [19]. In another study, the incidence of striae was reported $44 \%$ in cocoa users and $56 \%$ in the control group [20]. The present study results agree with those obtained in the above studies.

A study conducted by Behnia and Hosseini on 31 women showed the effectiveness of sweet almond oil in both prevention of striae and its associated itching and also improving previous striae [21]. It has been found that a teak wood cream containing lanolin, stearin, triethanolamine, almond oil, and glycerin amidine beeswax is effective in preventing striae gravidarum [3]. In a study in Japan by Young and Jewell conducted on 80 pregnant women (41 in the intervention group and 39 in control), the intervention group received a kind of 
Table 2: Mean length and width of striae in either trial or control sides before and after intervention

\begin{tabular}{|c|c|c|c|c|c|c|c|}
\hline \multirow{3}{*}{$\begin{array}{l}\text { Striae } \\
\text { characteristics }\end{array}$} & \multirow[t]{3}{*}{ Study Phase } & \multirow[t]{3}{*}{ Groups } & \multirow{3}{*}{$\begin{array}{l}\text { Amounts } \\
\text { in mm, } \\
\text { mean (SD)* }\end{array}$} & \multicolumn{2}{|l|}{ Between groups } & \multirow{2}{*}{\multicolumn{2}{|c|}{$\begin{array}{l}\text { Within groups } \\
\text { Statistical test }(P)\end{array}$}} \\
\hline & & & & Statistical test & $P$ & & \\
\hline & & & & & & Experimental group & Control group \\
\hline \multirow[t]{3}{*}{ Length } & Before & Experimental & $45.92(17.23)$ & Paired samples $t$-test & $P=0.83$ & $\begin{array}{l}\text { Paired samples } \\
t \text {-test }(P<0.001)\end{array}$ & $\begin{array}{l}\text { Paired samples } \\
t \text {-test }(P=0.45)\end{array}$ \\
\hline & & Control & 42.82 (18.77) & & & & \\
\hline & After & $\begin{array}{l}\text { Experimental } \\
\text { Control }\end{array}$ & $\begin{array}{l}39.88(15.61) \\
43.79(16.25)\end{array}$ & Paired samples $t$-test & $P=0.30$ & & \\
\hline \multirow[t]{3}{*}{ Width } & Before & Experimental & $5.55(2.05)$ & Paired samples $t$-test & $P=0.15$ & $\begin{array}{l}\text { Paired samples } \\
t \text {-test }(P<0.001)\end{array}$ & $\begin{array}{l}\text { Paired samples } \\
t \text {-test }(P=0.20)\end{array}$ \\
\hline & & Control & $5.12(2.07)$ & & & & \\
\hline & After & $\begin{array}{l}\text { Experimental } \\
\text { Control }\end{array}$ & $\begin{array}{l}4.96(1.84) \\
5.03(2.05)\end{array}$ & Paired samples $t$-test & $P=0.80$ & & \\
\hline
\end{tabular}

*Data available for 23 participants. SD: Standard deviation

cream called trofolastin containing tocopherol collagen and elastin hydrolyzate, and control group received placebo from $12^{\text {th }}$ gestational week to childbirth. The results obtained showed 56\% incidence of striae in the control group and 36\% in the intervention [27]. In their study, Osman et al. reported incidence of striae $48.8 \%$ of cocoa cream users and $45.1 \%$ in the control group [28,29]. The results of these studies disagree with the present study results, probably due to the difference in study objectives, which were treatment in the present study, and prevention in most of the above studies. Moreover, the difference in the target group, type and time of intervention, and sample size may be other reasons.

No similar study to the present study was found in terms of the application of apple vinegar for the treatment and prevention of striae gravidarum. However, use of apple vinegar for treatment of vaginal and skin fungal infections has produced useful results [30,31]. Given the positive effect of apple vinegar in reducing the size of striae, further studies on the effects of apple vinegar in preventing the incidence of striae gravidarum are recommended.

\section{CONCLUSION}

Topical application of apple vinegar is effective in reducing the size of striae. However, further and longer studies on larger sample sizes are necessary. It is recommended that the effects of apple vinegar be compared to other existing creams, oils, and medications.

\section{ACKNOWLEDGMENTS}

The authors wish to express their thanks to the Research and Technology Deputy and Health Deputy of Gonabad University of Medical Sciences, the management of health centers 1, 2, and 3 in Gonabad, and personnel of maternity units. We also thank colleagues for their help in the assessment and development of this study. We sincerely thank all participating mothers.

\section{CONFLICTS OF INTEREST}

The authors have no conflicts of interest.

\section{AUTHORS' CONTRIBUTION}

The conception and design of the study: Maryam Eshghizadeh. Acquisition of data: Zahra Rezvanifar, Mahdieh Atarodi, and Mahboobeh Baghban. Analysis and interpretation of data: Mahdi Basirimoghaddam. Drafting the article or revising it critically for important intellectual content: Samane Najafi, Maryam Eshghizadeh, Mahdi Basirimoghaddam, Zahra Rezvanifar, Mahdieh Atarodi, and Mahboobeh Baghban. Final approval of the version to be submitted: Samane Najafi, Maryam Eshghizadeh, Mahdi Basirimoghaddam, Zahra Rezvanifar, Mahdieh Atarodi, and Mahboobeh Baghban.

\section{REFERENCES}

1. Bahrami N, Soleimani MA, Shaighan H. Severity of striae gravidarum and its related factors in primiparous women. J Shahrekord Univ Med Sci 2013; 15:64-73.

2. Cunningham W. Pregnancy Williams. $1^{\text {st }}$ Printing. Tehran: Arjmand Publication; 2013.

3. Taavoni S, Soltanpour F, Haghani H, Ansarian H, Kheirkhah M. A servey of the effect of olive oil and saj cream on striae gravidarum in the second trimester of pregnanc. Iran J Nurs 2012;25:45-51.

4. Orh RJ, Titapant V, Chuenwattana P, Tontisirin P. Prevalence and associate factors for striae gravidarum. J Med Assoc Thailand 2008;91:445-51.

5. Moloody M, Rezaei ZH, Bahrami N, Soleimani MA. Striae gravidarum risk factors in primiparae pregnant women. J Urmia Nurs Midwifery Facult 2014;12:207-13.

6. Wong RC, Ellis CN. Physiologic skin changes in pregnancy. J Am Acad Dermatol 1984;10:929-40.

7. Shuster S. The cause of striae distensae. Acta Dermatol Venereol 1979;59 Suppl 85:161-9.

8. Waston RE, Parry EJ, Humphries JD, Jones CJ, Polson DW, Kiety CM, et al. Fibrillin microfibrils are reduced in skin exhibiting striae distansea. Br J Dermatol 1998;138:931-7.

9. Jomeen J, Martin CR. Self-esteem and mental health during early pregnancy. Clin Eff Nurs 2005;9:92-5.

10. Pelin KS, Eskiolu F. Striae gravidarum: Associated factors in Turkish primiparae. J Turk Acad Dermatol 2009;3:93401a.

11. Yamaguchi K, Suganuma N, Ohashi K. Qulity of life evaluation in Japanes pregnant women with striae gravidarum: A cross-sectional study. BMC Res Notes 2012;5:450-6.

12. Tunzi M, Gray GR. Skin condition during pregnancy. Am Fam Phys 2007;75:211-8.

13. Salter SA, Kimbell AB. Striae gravidatum. Clin Dermatol 2006;24:97-100.

14. MCDaniel DH, Ash K, Zukowski M. Treatment of stretch marks with the 585-nm flashlamp-pumped pulsed dye laser. Dermatol Surg 1996;22:332-7.

15. Nussbaum R, Bennedetto AV. Cosmetic aspects of pregnancy. Clin Dermatol 2006;24:133-41.

16. Creasy RK, Resnik R. Maternal-Fetal medicine. $2^{\text {nd }}$ ed. Philadelpia, PA: WB Sunders Company; 1989.

17. Odey P. Herbs for a Healthy Pregnancy. Los Angeles, CA: McGraw Hill Professional; 1999. p. 42-4.

18. Taavoni S, Soltanpour F, Haghani H, Ansarian H, Kheirkhah M. Effect of olive oil on striae gravidarum in the second trimester of pregnanc. Complement Ther Clin Pract 2011;17:167-9.

19. Tashan ST, Kafkasli A. The effect of bitter almond oil and massaging on striae gravidarum in primiparaous women. J Clin Nurs 2012;21:1570-6.

20. Buchanan K, Fletcher HM, Reid M. Prevention of striae gravidarum with cocoa butter cream. Int J Gyn Obstet 2010;108:65-8.

21. Behnia H, Hosseini M. The protective effect of almond oil and glycerin in striae gravidarum. Pejouhandeh Res J 2000;19:317-20.

22. Malakouti J, Farshbaf A, Kamrani A. The effect of sesame oil and sweet almond prevention striae and itching of primipara women: A randomized controlled trial. Iran J Obstet Gyn Infert 2015;18:1-11. 
23. Bragg P, Paul C. The Miracles of Apples Cider Vinegar. Translated by Fallahi M, Panahi A. $3^{\text {rd }}$ edition. Mashhad: Shahin Publication; 1982.

24. Karimi K, Gholizadeh G. Health and Beauty in the Delicate Flowers. Tehran: Noandish Publication; 1999

25. Gandy M, Grammer J. Effect of Graston Technique on Post-gravid Stretch Marks. Logan College of Chiropractic; 2011.

26. Suh DH, Lee SJ, Lee JH, Kim HJ, Shin MK, Song KY, et al. Treatment of striae distensae combined enhanced penetration platelet-rich plasma and ultrasound after plasma fractional radiofrequency. J Cosmet Laser Ther 2012;14:272-6.

27. Young G, Jewell D. Creams for preventing stretch marks in pregnancy. Cochrane Database of Syst Rev 1996;1:1-9.

28. Osman H, Usta IM, Rubeiz N, Abu-Rustum R, Charara I, Nassar AH. Cocoa butter lotion for prevention of striae gravidarum: A double- blind, randomized and placebo controlled trial. J Obstet Gynecol 2008;28:1137-42.

29. Kaivani M, Sepahi S, Azima S, Emamghoreishi M, Asadi N, Haghpanah S. The effects of olive leaf extract ointment on pain intensity and early maternal complications in primiparous women. Int J Pharm Pharm Sci 2017;9:31-4

30. Mohammadpour A, Najafi S, Tavakkolizadeh J, Mohammadzadeh F. The effect of intervention based on "Roy" adaptation model on personal self-concept in primi-gravida women. J Sabzevar Univ Med Sci 2015;22:999-1007.

31. Mohammadpour A, Najafi S, Tavakkolizadeh J, Mohammadzade F. The effects of the Roy's adaptation model on primigravida women's selfconcept: A randomized controlled trial. Asian J Pharm Res Health Care 2016;8:17-23. 